\title{
Dificuldades para obter informações da população de mulheres sobre aborto ilegal*
}

\section{Difficulties encountered in gathering information on illegal abortion of women population}

\author{
Maria José D. Osis, Ellen Hardy, Anibal Faúndes e Telma Rodrigues \\ Centro de Pesquisas das Doenças Materno-Infantis de Campinas. Campinas, SP - Brasil (M. J. D. O., \\ T. R.), Departamento de Tocoginecologia da Faculdade de Ciências Médicas da Universidade \\ Estadual de Campinas. Campinas, SP - Brasil (E. H., A. F.)
}

\begin{abstract}
Resumo
Qualquer tentativa de se investigar a prática de abortos ilegais deve lidar com o problema de estar perguntando às mulheres acerca de um tema delicado, sensível, com implicações múltiplas, o que leva a dificuldades para se obter informações verazes. O estudo realizado enfoca principalmente aspectos metodológicos de uma pesquisa realizada junto a uma população de mulheres de 15 a 49 anos de idade, com o objetivo de verificar a frequiência e as condições em que era feito o aborto provocado em uma região do Estado de São Paulo (Brasil). Foram entrevistadas, em seus domicílios, 1.955 mulheres. Utilizou-se um questionário estruturado e pré-testado. A maioria das entrevistadas declarou nunca ter abortado nem pensado em fazê-lo, enquanto $4 \%$ referiram alguma vez ter feito aborto; $16,7 \%$ disseram que, pelo menos uma vez, tomaram chá/remédio para menstruar. Entre as que acreditaram estar grávidas na ocasião, a maioria informou nunca ter abortado, apesar de terem menstruado quando ingeriram chá/remédio. Os resultados permitiram concluir que as mulheres tendem a omitir a informação sobre a prática de aborto quando perguntadas diretamente sobre isso. Especialmente aquelas que o induzem por ingestão de substâncias parecem não reconhecer esse ato como sendo uma forma de interromper a gestação.
\end{abstract}

Aborto induzido, epidemiologia.

\begin{abstract}
Any attempt to study the practice of illegal abortion faces the problem of asking women about a delicate, sensitive issue that has many implications. This may make it difficult to obtain truthful information on the subject. Results related to methodological aspects are emphasized and their possible association with variables included in a cross-sectional study carried out among 1.955 women, of 15 to 49 years of age is analysed. The frequency and conditions under which induced abortion was performed in a region of S. Paulo State are investigated. The women were interviewed at home using a pre-tested, structured question-
\end{abstract}

\footnotetext{
* Pesquisa subvencionada pela Fundação Ford, Programa de Saúde Reprodutiva.

Correspondência para/Correspondence to: Maria José D. Osis - Centro de Pesquisas das Doenças Materno-Infantis de Campinas. Caixa Postal 6181

- 13081-970 Campinas, SP - Brasil. Fax:(019) 239.2440 E-mail: cemicamp@ turing.unicamp.br

Edição Subvencionada pela FAPESP. Processo 95/2290-6.

Recebido em 7.11.1995. Reapresentado em 14.3.1996. Aprovado em 3.4.1996.
} 
naire. Most of the women interviewed declared they had never had an abortion nor had they thought of having one, and four percent referred to having had an induced abortion. However, another 16.7 percent said that they had taken tea or medicine at least once to bring on their menses. In this group, most of the women who thought they were pregnant at that time said they had had never an abortion, in spite of having bled after drinking tea or medicine. The results lead to the conclusion that women tend no omit information on the practice of abortion when questioned directly. This is especially true of those who use oral means to bring on their menses and who seemed not to consider this a way of inducing an abortion.

Induced abortion, epidemiology.

\section{INTRODUÇÃO}

O aborto provocado no Brasil é crime, exceto em caso de estupro ou risco de vida materna, conforme os artigos 124 a 128 do Código Penal (Brasil $\left.{ }^{5}, 1940\right)$. Apesar disso, há evidências de que ele é amplamente praticado. Estimativas do Ministério da Saúde afirmam que são feitos no País cerca de 1.200.000 abortos por ano $\left(\mathrm{Costa}^{6}, 1992\right)$, enquanto que a estimativa do Instituto Alan Guttmacher (AGI $\left.{ }^{1}, 1994\right)$ foi de 1.443.350.

A ausência de dados abrangentes e confiáveis sobre o assunto deve-se a que, dadas as restrições legais ao aborto provocado no Brasil, a pesquisa acerca dele é dificultada. Os dados a que se tem acesso são, em sua maioria, resultados de pesquisas ou levantamentos feitos em hospitais, especialmente nos que atendem à população de menor renda (Fariña ${ }^{9}$, 1975; Boehs e col. ${ }^{4}, 1983$; Schor $^{13}$, 1990). Segundo estimativa feita a partir da pesquisa de opinião sobre prática de aborto no Brasil (AGI $\left.{ }^{1}, 1994\right)$, cerca de $40 \%$ das mulheres que fazem abortos neste País têm complicações e $30 \%$ chegam a ser internadas por isso. Como a maior proporção de complicações é verificada entre as mulheres mais pobres, são estas que, principalmente, recorrem aos hospitais públicos para tratamento das complicações, fazendo com que as informações oficialmente disponíveis refiram-se praticamente apenas a esse subgrupo das que fazem aborto: as mais pobres e que tiveram algum tipo de complicação que motivou a internação.

Qualquer tentativa de se investigar o assunto deve lidar com o problema de se estar perguntando às mulheres acerca de um tema delicado, sensível, com implicações múltiplas. Mais à superfície, pode-se pensar que as mulheres não queiram admitir a prática de aborto por que isso infringe o código penal. Entretanto, pelo que se pode acompanhar na imprensa em geral, são poucos os casos em que mulheres, médicos ou aborteira(o) têm chegado a julgamento por ter feito um aborto.

Isso sugere que há outros fatores, além da possível penalização legal, que interferem na postura das mulheres quanto a admitirem ou não a prática do aborto. Existem aspectos psicológicos, morais, religiosos e culturais associados não só à decisão de se fazer um aborto, mas também de como reagir e a falar ou não sobre ele. Hardy e col. ${ }^{11}$ (1991), por exemplo, estudaram um grupo de 1.314 mulheres que tinham engravidado pelo menos uma vez, e constataram que, entre as 369 que declararam já terem pensado em abortar, sua crença religiosa estava estatisticamente associada a ter feito ou não o aborto: $84 \%$ das mulheres que se declararam sem religião tinham abortado, comparadas com $75 \%$ das que se declararam seguidoras da umbanda ou de outras religiões, $71 \%$ das espíritas, $67 \%$ das católicas e $50 \%$ das evangélicas/protestantes.

Outros resultados da pesquisa acima citada indicam que as razões para fazer ou não um aborto não estão referidas diretamente ao medo de uma punição legal. Entre as 109 mulheres que disseram ter pensado em abortar e não o fizeram, a razão mais mencionada para isto foi "medo das conseqüências/não teve coragem". Entretanto, estas razões nunca incluiam o medo de serem presas. Eram, antes, consequiências em nível físico, psicológico ou moral. Assim, 83\% das mulheres que terminaram não fazendo o aborto disseram ter se sentido bem, felizes, aliviadas, não arrependidas da decisão, enquanto $4,3 \%$ declararam ter ficado chateadas, frustradas e arrependidas. Por outro lado, quase a metade das que abortaram referiu ter se sentido mal emocional e/ou fisicamente após $o$ ato, enquanto mais de um quarto $(27,9 \%)$ disse ter se sentido bem (Costa e col. $\left.{ }^{8}, 1995\right)$.

Esse contraste de sentimentos, oscilando entre pensar em abortar e culpar-se por isto, deixar de fazêlo mas sentir-se frustrada, ou então aliviada/feliz por 
não ter feito, indica o quão profundamente o aborto sensibiliza as mulheres, fazendo-as sofrer física e emocionalmente. Essa sensibilização, provavelmente, é um dos fatores que contribui para que as mulheres estabeleçam, em sua racionalidade, distinção entre abortar e fazer alguma coisa para descer a menstruação, especialmente se a providência tomada nesse sentido significar apenas a ingestão de determinadas substâncias, como chás e/ou remédios, e nenhuma intervenção direta na região genital (Leal e Lewgoy ${ }^{12}$, 1994).

Induzir o aborto por via oral parece ser, inclusive, um dos elementos que facilitam a decisão de algumas mulheres abortarem. Em um estudo feito em São Paulo (Barbosa e Arilha ${ }^{3}$, 1992) a respeito do uso do Cytote ${ }^{\circledR}$ (misoprostol), por exemplo, observou-se que, especialmente entre as mulheres com menos de 20 anos, o acesso a esse medicamento facilitou a decisão de abortar. Primeiramente porque elas disseram que não teriam abortado se tivessem que ir a uma clínica para isso, de forma que o uso dessa substância tornou possível que o aborto acontecesse sem que tivesse sido racionalmente planejado. Em segundo lugar, esse não planejar permitiu a realização do aborto dentro de um contexto de ambigüidade, sem ser preciso assumilo explicitamente.

Parece claro, diante de tantas implicações, que falar sobre aborto não deve ser fácil para as mulheres, e o conjunto de sentimentos envolvidos deve contribuir para a dificuldade de se obterem dados precisos acerca do assunto. Coloca-se, portanto, a questão metodológica de como abordá-lo de forma a obter informações confiáveis. Como perguntar às mulheres e ter a mínima certeza de que elas responderam com veracidade? Será que a aplicação, por uma entrevistadora devidamente treinada, de um questionário estruturado e pré-testado pode permitir a obtenção de informações confiáveis sobre aborto provocado?

Para investigar esses aspectos metodológicos e também alguns temas relativos à prática do aborto (como, por exemplo, frequiência, a forma de indução, as condições de realização), foi feita uma pesquisa com mulheres de 15-49 anos de idade que incluiu, além de perguntas diretas sobre a prática de aborto, outras cujas respostas poderiam indicar que, apesar de não declararem, elas teriam tido abortos provocados.

O objetivo principal da presente pesquisa foi estudar a freqüência e as condições em que era feito o aborto provocado em uma determinada região do Estado de São Paulo.

\section{MATERIAL E MÉTODO}

O desenho do estudo foi do tipo transversal-retrospectivo. O tamanho amostral foi calculado em $1.801 \mathrm{mu}-$ lheres entre 15-49 anos de idade, que moravam nos domicílios visitados dos Municípios de Campinas e Sumaré, e que tiveram pelo menos uma gravidez. Esse cálculo foi baseado em uma proporção de $25 \%$ de abortos provocados, estimada na população (Galbinski ${ }^{10}, 1971$ ), com uma diferença de $2 \%$ entre a proporção populacional e amostral e com um intervalo de confiança de $95 \%$.

Para confirmar a veracidade das informações obtidas com a metodologia de pesquisa utilizada, investigou-se também mulheres que estiveram internadas por aborto em um hospital, da citada região, referiam este fato ao serem entrevistadas posteriormente em suas casas.

O levantamento hospitalar, mediante autorização expressa da direção da instituição, foi feito em julho de 1992, tendo sido examinados os prontuários de todas as mulheres internadas por complicações de aborto, entre julho de 1991 e junho de 1992, no hospital escolhido. Os casos de aborto foram classificados em espontâneos, provocados e suspeitos de serem provocados, segundo critérios propostos pela Organização Mundial da Saúde ${ }^{16}, 1978$. Os dados coletados do prontuário foram: data da internação, diagnóstico, data de nascimento e endereço de cada mulher. Em nenhum lugar ficou registrado o nome das mulheres, tampouco as entrevistadoras tinham conhecimento de que algumas das entrevistadas seriam aquelas sobre as quais sabia-se que tinham estado internadas por aborto.

Os domicílios visitados foram selecionados em setores censitários dos Municípios de Campinas e Sumaré, em que predominava a população de baixa renda, existindo diversas favelas. Na agência da Fundação IBGE de cada cidade foram obtidos mapas dos bairros em que se pretendia trabalhar, com a correspondente divisão em setores. Em um de cada oito domicílios foram entrevistadas todas as mulheres que cumpriam os critérios de inclusão. Ao final desse processo, 1.838 mulheres foram entrevistadas.

Além disso, foram procurados 100 domicílios pré-selecionados, correspondentes aos endereços informados pelas mulheres que haviam estado internadas. Esses domicílios foram selecionados com base no critério de se encontrarem nos setores censitários, incluídos no estudo ou próximos a eles. Através desse processo foram entrevistadas 107 mulheres, cujos dados, entretanto, não foram incluídos na análise apresentada nas Tabelas de 1 a 4 .

Os dados foram obtidos através de entrevistas individuais, realizadas, em agosto de 1992, nos domicílios selecionados. As entrevistadoras receberam treinamento para a seleção dos domicílios e para a coleta dos dados. Utilizou-se um questionário estruturado, pré-testado, com perguntas pré-codificadas e outras em que a resposta era anotada textualmente. Para assegurar o sigilo da fonte das informações, os questionários foram identificados apenas com um número. Saliente-se que as entrevistadoras não sabiam que algumas casas seriam visitadas justamente porque correspondiam a endereços de mulheres que tinham 
sido internadas no hospital acima referido. Elas apenas recebiam um endereço a mais para visitar, com a orientação de entrevistarem ali todas as mulheres elegíveis para o estudo.

Para investigar a frequiência de abortos provocados foram utilizadas diferentes formas de perguntar sobre o assunto. Para as mulheres que declararam abortos em sua história reprodutiva fez-se, primeiramente, uma abordagem direta, com perguntas sobre o último aborto, incluindo se este tinha sido espontâneo ou provocado. As que o declararam como tendo sido espontâneo passavam a uma seção do questionário, em que se perguntava se alguma vez haviam pensado em fazer aborto e, em caso positivo, se o fizeram.

Para todas as entrevistadas foi perguntado se alguma vez haviam tomado chá e/ou remédio para descer a menstruação, se esta descera e se elas acharam que estavam grávidas naquela ocasião. Para as que disseram ter tomado chá e/ou remédio, mas não referiram abortos, foram feitas perguntas sobre a última vez em que ingeriram essas substâncias com o propósito de menstruarem. Igualmente, foi perguntado a todas as mulheres incluídas no estudo se conheciam um medicamento chamado Cytotec $\AA$ (misoprostol) e, em caso positivo, se o haviam utilizado alguma vez e com que finalidade.

Para o processamento e análise dos dados foi utilizado o "Statistical Package for the Social Sciences" (SPSSPC). A significância das diferenças entre os grupos foi estudada com o teste qui-quadrado (Armitage e Berry ${ }^{2}$, 1971). Nas tabelas estão expressos apenas os valores de $\mathrm{p}<0,05$.

\section{RESULTADOS}

A maioria das entrevistadas declarou nunca ter abortado nem pensado em fazê-lo, enquanto $4 \%$ declararam alguma vez ter feito aborto. Entretanto, $16,7 \%$ das mulheres referiram que pelo menos uma vez tomaram chá/remédio para menstruar, quando tiveram algum atraso menstrual (Tabela 1).

Apenas cerca de um quarto das mulheres que disseram alguma vez ter tomado chá/remédio para menstruar, e que pensaram que estavam grávidas naquela ocasião, declarou ter provocado algum aborto. A proporção de mulheres que referiram nunca ter abortado foi semelhante (próxima de três quartos) no grupo das que disseram nunca ter tomado chá/remédio

Tabela 1 - História de aborto entre mulheres de 15-49 anos, alguma vez grávidas.

\begin{tabular}{lr}
\hline História do aborto & $\%$ \\
\hline Nunca abortaram, nem pensaram em abortar & 54,7 \\
Pensaram em abortar, mas não o fizeram & 6,4 \\
Só aborto espontâneo & 18,2 \\
Tomaram chá/remédio para menstruar & 16,7 \\
Provocaram aborto & 4,0 \\
\hline Total de mulheres* & 1.834 \\
\hline * Faltou informação de quatro mulheres.
\end{tabular}

para menstruar, das que tomaram e não menstruaram e daquelas que menstruaram e não acharam que estavam grávidas naquela ocasião. No grupo das que tomaram chá/remédio, menstruaram e julgaram estar grávidas, pouco mais da metade disse nunca ter abortado. As diferenças entre os grupos foram estatisticamente significativas (Tabela 2).

Considerando todas as mulheres que declararam alguma vez ter tomado chá/remédio para menstruar, a proporção com atraso menstrual de mais de quatro semanas, nesse momento, foi maior entre aquelas em que a menstruação desceu do que no grupo das que não sangraram, sendo as diferenças estatisticamente significativas (Tabela 3 ). Limitando a análise ao subgrupo das que menstruaram tomando chá/remédio, verificou-se que a percentagem de entrevistadas que tinham apenas alguns dias de atraso menstrual não foi significativamente maior no grupo das que não acharam estar grávidas do que entre as que pensaram estar. $\mathrm{O}$ mesmo se verificou em relação às mulheres que tinham mais de dois meses de atraso menstrual quando usaram chá/remédio (Tabela 4).

Perguntou-se às entrevistadas com quanto tempo de atraso menstrual julgavam que uma mulher estaria grávida. Observando-se mais detalhadamente o grupo de mulheres que tinham mais de um mês de atraso menstrual, quando tomaram chá/remédio e menstruaram, não houve diferenças significativas entre as que acharam ou não estar grávidas. Verificou-se que cerca de dois quintos das que não se consideraram grávidas naquela ocasião referiram que uma mulher estaria grávida se tivesse mais de um mês de atraso. Entre as entrevistadas que disseram ter achado estar grávidas, menos da metade considerou que uma mulher estaria grávida se tivesse mais de um mês de atraso menstrual (Tabela 5).

Finalmente, através de uma seção do questionário que investigou especificamente o conhecimento e uso do Cytotec ${ }^{\circledR}$, identificaram-se oito mulheres que não referiram o uso de chá/remédio para menstruar, mas disseram ter usado esse medicamento pelo menos uma vez, ou para fazer descer a menstruação ou para abortar; entretanto, quatro delas não declararam abortos, apesar de duas terem dito explicitamente que usaram o Cytotec ${ }^{\circledR}$ para abortar, enquanto as outras duas mencionaram que o usaram para fazer descer a menstruação.

Dos 100 endereços de mulheres que estiveram internadas por aborto ou suspeita de aborto, foram encontrados 60. Os demais não existiam ou eram estabelecimentos comerciais. Em cinco deles não se conseguiu entrevistar ninguém, mesmo após três tentativas. Nos outros 55 foram entrevistadas todas as 
Tabela 2 - Distribuição percentual das mulheres segundo história de aborto e se tomaram chá/remédio para menstruar, se isto ocorreu e se acharam estar grávidas.

\begin{tabular}{lcccc}
\hline & \multicolumn{3}{c}{ Tomaram chá/remédio } \\
\cline { 2 - 5 } História de aborto & $\begin{array}{c}\text { Não } \\
\text { tomaram* }\end{array}$ & $\begin{array}{c}\text { Tomaram e não } \\
\text { menstruaram }\end{array}$ & $\begin{array}{c}\text { Tomaram e menstruaram** } \\
\text { Pensaram estar grávidas }\end{array}$ \\
\cline { 3 - 6 } & & 72 & Sim & Não \\
\hline Nunca abortou & 75,8 & 21 & 56,4 & 72,0 \\
Espontâneo & 22,6 & 7 & 24,8 & 25,0 \\
Provocado & 1,6 & 81 & 149 & 200 \\
\hline Total & 1.405 & & & \\
\hline
\end{tabular}

$\mathrm{p}<0,0001$

* Faltou informação de uma mulher.

** Faltou informação de duas mulheres.

Tabela 3 - Distribuição percentual das mulheres segundo tempo de atraso menstrual quando tomaram chá/remédio e se menstruaram ou não.

\begin{tabular}{llc}
\hline & \multicolumn{2}{c}{ Menstruaram } \\
\cline { 2 - 3 } Tempo de atraso & Sim & Não \\
\hline Até uma semana & 22,1 & 17,0 \\
+ de 1 até 4 semanas & 39,3 & 54,0 \\
+ de 1 até 2 meses & 23,1 & 10,0 \\
+ de 2 até 3 meses & 15,5 & 15,0 \\
\hline Total & $303^{*}$ & $79 * *$ \\
\hline p $<0,02$ & & \\
** Faltou informação de 12 mulheres e 34 não lembravam o tempo. \\
Faltou informação de uma mulher e quatro não lembravam o tempo.
\end{tabular}

Tabela 4 - Distribuição percentual das mulheres segundo tempo de atraso menstrual quando tomaram chá/remédio com sucesso e se acharam estar grávidas

\begin{tabular}{lcc}
\hline & \multicolumn{2}{c}{ Pensaram estar grávidas } \\
\cline { 2 - 3 } Tempo de atraso & Sim & Não \\
\hline Até uma semana & 18,7 & 25,1 \\
+ de 1 até 4 semanas & 44,8 & 34,1 \\
+ de 1 até 2 meses & 24,6 & 22,2 \\
+ de 2 meses & 11,9 & 18,6 \\
\hline Total & $134^{*}$ & $168^{* *}$ \\
\hline
\end{tabular}

* Faltou informação de nove mulheres e seis não lembravam.

** Faltou informação de quatro mulheres e 28 não lembravam.

mulheres ali residentes e que cumpriam os critérios de seleção do estudo, totalizando 107 entrevistas. Em 25 desses endereços não se conseguiu identificar as mulheres que poderiam corresponder às que tinham estado internadas no hospital.

Em 30 domicílios foi possível identificar uma entrevistada cujo ano de nascimento coincidia com alguém na lista hospitalar. Apenas a metade dos abortos sabidamente provocados foram declarados como tais durante a entrevista, e nenhum dos 13 suspeitos foram referidos como provocados pelas entrevistadas, sendo que duas nem sequer informaram ter tido qualquer aborto. Por outro lado, das nove mulheres cujo aborto no hospital não foi identificado como provocado e nem mesmo suspeito, uma declarou que provocou o aborto e outra negou ter tido qualquer aborto (Tabela 6).
Tabela 5 - Distribuição percentual das mulheres com mais de um mês de atraso menstrual que acharam ou não estar grávidas, segundo tempo de atraso para considerar que uma mulher está grávida.

\begin{tabular}{lcc}
\hline & \multicolumn{2}{c}{ Pensaram estar grávidas } \\
\cline { 2 - 3 } Tempo de atraso & Sim & Não \\
\hline Até uma semana & 5 & 3 \\
+ de 1 até 4 semanas & 51 & 57 \\
+ de 1 até 2 meses & 22 & 25 \\
+ de 2 meses & 22 & 15 \\
\hline Total & 49 & $65^{*}$ \\
\hline
\end{tabular}

* Quatro mulheres não sabiam dizer com quanto tempo de atraso consideravam que uma mulher está grávida.

Tabela 6 - Comparação entre o tipo de aborto das mulheres identificadas: registro no hospital x entrevista.

\begin{tabular}{lcccc}
\hline \multirow{2}{*}{ Hospital } & \multicolumn{4}{c}{ Entrevista } \\
\cline { 2 - 5 } & $\begin{array}{c}\text { Provo- } \\
\text { cado }\end{array}$ & $\begin{array}{c}\text { Espon- } \\
\text { tâneo }\end{array}$ & $\begin{array}{c}\text { Negou } \\
\text { aborto }\end{array}$ & $\begin{array}{c}\text { Total de } \\
\text { mulheres }\end{array}$ \\
\hline Provocado & 4 & 2 & 2 & 8 \\
Suspeito & 0 & 11 & 2 & 13 \\
Espontâneo & 1 & 7 & 1 & 9 \\
\hline Total & 5 & 20 & 5 & 30 \\
\hline
\end{tabular}

\section{DISCUSSÃO}

Os resultados permitem dizer que as mulheres tendem a omitir a informação sobre prática de aborto quando perguntadas diretamente sobre o assunto. Além disso, percebe-se que aquelas que o induzem através da ingestão de chá/remédio, freqüentemente, não reconhecem esse ato como equivalente a fazer um aborto. Isto se confirma porque menos de $5 \%$ das entrevistadas declararam alguma vez ter feito um aborto, mas uma percentagem quatro vezes maior, embora não tenha referido aborto provocado, admitiu ter ingerido qualquer substância com a finalidade de menstruar e, entre essas, quatro quintos menstruaram, sendo que mais de dois quintos julgaram estar grávidas naquela ocasião. Além disso, não se verificaram diferenças entre as que julgaram ter estado grávidas e as demais 
quanto ao tempo de atraso menstrual que tinham quando usaram chá/remédio, nem quanto ao tempo de falta de regras que consideravam indicativo de que uma mulher estaria grávida.

Considerando a metodologia que foi empregada no presente estudo, pode-se inferir que, quando se abordam as mulheres diretamente a respeito de história de aborto em suas vidas, provavelmente serão obtidas informações não tão verazes quanto seriam necessárias para se fazerem afirmações a respeito da proporção de abortos provocados nas diversas populações. Confirmam essa suposição também os resultados encontrados por Silva ${ }^{14}$ (1992) em uma pesquisa desenvolvida na cidade de São Paulo com duas amostras de mulheres. Em uma delas (A) fez-se a abordagem direta sobre a prática de abortos durante o ano de 1987. Na outra amostra (B) utilizou-se a Técnica de Resposta ao Azar (TRA), uma forma indireta de abordar o assunto. Entre as gestações da amostra A foram declarados $8,2 \%$ de abortos provocados, comparados com $31,3 \%$ encontrados com a técnica utilizada na amostra B.

Os presentes resultados também apontam a tendência a negar a prática do aborto mesmo quando as mulheres foram internadas como resultado de suas complicações, como foi o caso de 11 entrevistadas das quais se sabia que tinham sido internadas no ano anterior por complicações de aborto considerado suspeito nos registros hospitalares, mas na entrevista referiram que o aborto tinha sido espontâneo. Por outro lado, esses resultados também indicam que a classificação dos abortos baseada em critérios clínicos nem sempre é inteiramente confiável para se estudar a frequiência de abortos provocados. Veja-se, por exemplo, que, das nove mulheres cujos registros no hospital eram de aborto espontâneo, na entrevista uma declarou que tivera um aborto provocado enquanto outra negou qualquer aborto, o que faz pensar que, provavelmente, aquele que estava registrado no hospital fora na verdade provocado.

Essa tendência a negar a prática do aborto tem sido detectada também em estudos hospitalares. Fariña $^{9}$ (1975), por exemplo, estudou 300 gestantes internadas com abortamento incompleto, entrevistando-as três ou mais vezes. Na primeira entrevista, $90 \%$ das mulheres atribuiu o aborto a quedas acidentais ou sustos. A partir do segundo contato, todas as 300 declararam que haviam provocado o aborto. Isto indica que existe certa resistência das mulheres em assumirem frente a um estranho(a) a indução do aborto, mas que é possível vencer esse desconforto mediante o estabelecimento de um contato pouco mais aprofundado, como é o caso de entrevistas sucessi- vas com a mesma pessoa. Entretanto, em pesquisas com amostras populacionais, como a que originou o presente trabalho, esse tipo de aprofundamento é impossível. Foi por essa razão que se adotou a estratégia, descrita na metodologia, de fazer diferentes tipos de perguntas que permitissem, mesmo que indiretamente, checar a informação das mulheres acerca de sua história de aborto.

Outro ponto importante é o freqüente não reconhecimento do aborto quando induzido por via oral, pela ingestão de chá e/ou remédio. Esse fenômeno foi analisado, com instrumental analítico da antropologia, por Leal e Lewgoy ${ }^{12}$ (1994). Esses autores usaram dados etnográficos de uma pesquisa sobre práticas reprodutivas e contraceptivas, realizada em Porto Alegre, e seus resultados também indicaram o não reconhecimento das chamadas chapueradas (chás para descer a menstruação, combinados ou não com elementos químicos) como métodos abortivos. Para os pesquisadores isso indica que seus entrevistados faziam uma leitura social dos sinais e estados do corpo, de maneira que a alteração apresentada pelo corpo - a ausência da menstruação, era ou não considerada como indicadora de uma possível gravidez, conforme o contexto social daquele momento.

Segundo Leal e Lewgoy ${ }^{12}$ (1994) existe um período limiar entre a transformação de uma gravidez biológica em social, em que os sintomas físicos são interpretados à luz das condições sociais que as pessoas têm para assumirem a gravidez. Entre essas condições destacam-se a estabilidade da relação que originou a gravidez, o número prévio de filhos e as condições (não só econômicas) de educar a criança. Além disso, esses autores consideram que o uso de substâncias por via oral freqüentemente não é considerado como abortivo porque não existe uma associação direta com a gravidez, ao contrário de outros procedimentos por via vaginal em que se estabelece uma ligação imediata com a gestação. Igualmente, Barbosa e Arilha $^{3}$ (1992), pesquisando a utilização de Cytotec ${ }^{\circledR}$ para induzir aborto, apontaram que a facilidade de aceitação desse medicamento como abortifaciente estava relacionada, entre outras coisas, à ambigüidade que ele permitia manter quanto à decisão de abortar, não exigindo das mulheres nenhuma atitude tão explícita quanto procurar uma clínica para fazer curetagem ou aspiração.

Os presentes resultados, embora advenham de um estudo quantitativo, pelas especificidades com que o instrumento de coleta de dados foi desenhado, investigando diferentes maneiras de se admitir a prática do aborto, permitem aprofundar alguns aspectos qualitativos de análise. E esses aspectos parecem 
corroborar as interpretações acima explicitadas, na medida em que foi detectado grupo de mulheres que não referiram abortos provocados mas, em outra parte do questionário, admitiram o uso de chá/remédio quando tiveram atraso menstrual, sendo que menstruaram, e naquela ocasião elas julgaram estar grávidas. Além delas, outras mulheres também ingeriram alguma substância para menstruar, não se julgaram grávidas, mas quando perguntado com quanto tempo de atraso menstrual uma mulher estaria grávida, a resposta coincidiu com o tempo de atraso que elas mesmas tinham na ocasião em que tomaram chá/ remédio para descer a menstruação. Através da investigação sobre o uso de Cytotec $\AA$, feita para todas as mulheres, também foi possível detectar como as mulheres, pelo menos até certo ponto, se valem da ambigüidade de induzir um aborto por via oral para não necessitarem assumir essa decisão, que certamente tem um peso muito grande sobre elas.

Quando se observam as discussões que acompanham o debate acerca do aborto em eventos como a Conferência Internacional sobre População e Desenvolvimento no Cairo, em 1994, e a Conferência Mundial da Mulher, realizada na China em setembro de 1995, evidenciam-se os focos de pressão sobre as mulheres e que, certamente, influenciam sua decisão e seus sentimentos em relação ao aborto. Os diferentes atores presentes a essas conferências, como as grandes potências do Norte e do Sul, os ambientalistas, as diferentes correntes religiosas e os grupos de mulheres tiveram enorme dificuldade para encontrar algum consenso acerca do aborto que preservasse as posições fundamentais de cada facção, tal a polêmica suscitada pelo assunto. É preciso lembrar que para além, e antes mesmo, dos documentos oficiais, estão as mulheres em seu cotidiano, metabolizando essas pressões de forma direta. Aquilo que a mídia mostra como discussões acaloradas nos ple- nários internacionais é vivenciado pelas mulheres em termos de acusações e discriminações frente a uma gravidez não desejada e à decisão de abortar ou não.

Essas considerações levam a concordar que existem, realmente, outros fatores, além dos sintomas biológicos, por mais claros que sejam, que fazem com que as mulheres se considerem grávidas ou não em determinadas circunstâncias. Conseqüentemente, esses fatores também determinam se elas vão reconhecer ou não que fizeram um aborto quando ingeriram qualquer substância, supostamente para resolver um atraso menstrual.

Percebe-se, portanto, que a questão metodológica sobre como investigar a freqüência de abortos provocados e as condições em que são feitos, através de estudos com base populacional, não encontra obstáculo apenas por se abordar uma prática punível judicialmente. Mais importante que isso parece ser a interpretação das mulheres acerca de quando há ou não uma gravidez, conseqüentemente, sobre quando há ou não aborto. Além disso, admitir ou não a prática do aborto está relacionado ao significado da gravidez indesejada e da sua interrupção ou não no imaginário de cada mulher. Sendo assim, por mais que se assegure o anonimato e o sigilo das pesquisas às mulheres, como nos estudos em que se utilizam questionários auto-respondidos (Costa e $\mathrm{col}^{7}, 1994$; Zamudio e col. $\left..^{15}, 1994\right)$, há que se contar com a influência da interpretação e do imaginário acima referidos no que diz respeito à confiabilidade dos dados a serem obtidos.

Desta forma, se é importante na conjuntura brasileira ainda investigar a frequiência de abortos provocados, é preciso que os pesquisadores tenham em mente os fatores subjacentes à questão sobre qual é a melhor metodologia a ser utilizada, para que os resultados contribuam para a resolução desse problema de saúde pública que é o aborto provocado.

\section{REFERÊNCIAS BIBLIOGRÁFICAS}

1. THE ALAN GUTTMACHER INSTITUTE. Aborto clandestino: uma realidade latino-americana. Nova Iorque, AGI, 1994.

2. ARMITAGE, P. \& BERRY, G. Statistical methods in medical research. 2nd ed. Oxford, Blackwell Scientific Publication, 1987.

3. BARBOSA, M.R. \& ARILHA, M. A experiência brasileira com o Cytotec ${ }^{\circledR}$. [Trabalho apresentado no 8th International Meeting of The Society for the Advancement of Contraception, Barcelona, 1992].
4. BOEHS, A.E.; SANTOS, E.K.F.; HASSE M.; SOUZA, M.L. Aborto provocado: estudo epidemiológico descritivo numa maternidade de Florianópolis, Santa Catarina. Ciênc. Cult., 35:501-6, 1983.

5. BRASIL. Leis, etc. Decreto-Lei n ${ }^{\circ} 2848$, de 7 de dezembro de 1940.

6. COSTA, A.M. O PAISM: uma política de assistência integral à saúde da mulher a ser resgatada. São Paulo, Comissão de Cidadania e Reprodução, 1992. 
7. COSTA, R.G.; OSIS, M.J.D.; HARDY, E. Metodologias usadas para estudar frequiência e questões relativas ao aborto provocado: principais problemas e vantagens. In: Encuentro de Investigadores sobre Aborto Inducido en América Latina y el Caribe - Aspectos metodológicos, Santa Fé de Bogotá, 1994. Anais, p. 35-42.

8. COSTA, R.G.; HARDY, E.; OSIS, M.J.D.; FAÚNDES, A. A decisão de abortar: processo e sentimentos envolvidos. Cad. Saúde Pública, 11:97-105, 1995.

9. FARIÑA, E.B. Estudo dos motivos, processos e conseqüências do abortamento em população assistida no Pronto-Socorro Obstétrico do Amparo Maternal. Rev. Esc. Enferm. USP, 9:323-46, 1975.

10. GALBINSKI, A. Contribuição ao estudo da epidemiologia do aborto provocado. J. Bras. Ginecol., 71:201-8, 1971.

11. HARDY, E.; REBELLO, I.; RODRIGUES, T.; MORAES, T.M. Aborto provocado: diferenças entre pensamento e ação. Rev. Ginecol. Obstet., 2:111-6, 1991.
12. LEAL, O.F. \& LEWGOY, B. Pessoa, aborto e contracepção. [Trabalho apresentado na 19ª Reunião da Associação Brasileira de Antropologia, Niterói, 1994.]

13. SCHOR, N. Investigação sobre ocorrência de aborto em pacientes de hospital de centro urbano do Estado de São Paulo, Brasil. Rev. Saúde Pública, 24:144-51, 1990.

14. SILVA, R.S. Aborto provocado: sua incidência e características. São Paulo, 1992. [Tese de doutoramento Faculdade de Saúde Pública da USP].

15. ZAMUDIO, L.C.; RUBIANO, N.B.; WARTENBERG, L.V. Representatividad, confiabilidad y significación: problemas prácticos de la investigación sobre aborto inducido. In: Encuentro de Investigadores sobre Aborto Inducido en América Latina y el Caribe - Aspectos Metodológicos, Santa Fé de Bogotá, 1994. Anais. p. 43-55.

16. WORLD HEALTH ORGANIZATION. Induced abortion: report of WHO scientific group. Geneva, 1978. (WHO - Technical Series, 623). 